https://doi.org/10.46813/2020-130-169

\title{
DISCHARGE CHARACTERISTICS OF COMBINED LOW ENERGY ION SOURCE - MAGNETRON SPUTTERING SYSTEM
}

\author{
A. Zykov, N. Yefymenko, S. Dudin, S. Yakovin \\ V.N. Karazin Kharkiv National University, Kharkiv, Ukraine \\ E-mail: zykov@karazin.ua
}

The discharge characteristics of a new combined low energy magnetron-ion-source sputtering system are presented. The ignition curves, current-voltage characteristics of the system in dependence on gas pressure, magnitude and topology of magnetic field have been researched both for autonomous operation of the planar magnetron discharge and Hall type ion source in plasma mode and for their combination. Spatial distributions of ion current are also presented.

PACS: 52.77.-j, 81.15.-z

\section{INTRODUCTION}

Ion assisted deposition of thin-film coatings is a proven technology providing improved coating properties with the possibility of control of phase composition, hardness, internal stress, etc. [1-5]. It is known that the energy flux to the growing film surface is one of the key factors governing the coating properties. The energy deposition due to ion bombardment is defined by product of ion energy and current density, and experiments show that the coating properties depend on the both factors independently [5]. Further research in this direction is of great interest, but the experiments require a tool allowing regulation of ion energy and current density independently from the deposition rate. An additional problem appears when the coating material is insulating, so the ion energy control by the sample biasing is impossible.

In response to this challenge different systems were used combining magnetron sputtering with separate plasma and ion sources [6-8]. The next step in this direction is the development of combined system joining the sources of deposited atoms and assisting ions in a single device. Such a combined magnetron-ion-source sputtering system (MISSS) was described in $[9,10]$. The system combines a magnetron and a Hall type ion source possessing common magnetic system. This allows to adjust the ion bombardment of the growing film controlling independently ion current density within the range of $0.1 \ldots 10 \mathrm{~mA} / \mathrm{cm}^{2}$ and average ion energy $(300 \ldots 1000 \mathrm{eV})$. MISSS provides deposition rate up to $3 \mathrm{~nm} / \mathrm{s}$ at the gas pressure $0.5 \ldots 10 \mathrm{mTorr}$.

Despite the proven efficiency of the mentioned device, not all of its parameters are optimal. Particularly, ion beam energy is too high for ion assistance of the film deposition, and the ion flow to the surface is significantly inhomogeneous.

In the present paper a new version of MISSS is presented and characterized, which allows to avoid the mentioned drawbacks preserving all the positive features. The system combines a magnetron with an EndHall ion source providing ion current density of $0.1 \ldots 5 \mathrm{~mA} / \mathrm{cm}^{2}$ and average ion energy of $30 . .300 \mathrm{eV}$. This energy range is most effective just for the film growth control without significant sputtering. Similarly to [8] this device uses the magnetron for deposition and ISSN 1562-6016. BAHT. 2020. №6(130)

PROBLEMS OF ATOMIC SCIENCE AND TECHNOLOGY. 2020, № 6. Series: Plasma Physics (26), p. 169-173. the End-Hall ion source for ion assistance, but in contrast, our system is axially symmetrical providing high homogeneity of processing.

\section{EXPERIMENTAL SETUP}

The schematic diagram of the new version of combined ion source- magnetron sputtering system with diagnostic equipment is presented in Fig. 1. The system consists of a conical end-Hall ion source (IS) [8] and a planar magnetron integrated into a joint structure. In comparison with the device presented in $[9,10]$ the key novelty is the widening the gap between the cathodes of the ion source to $15 \mathrm{~mm}$. This has allowed to optimize the plasma mode of the Hall-type ion source.

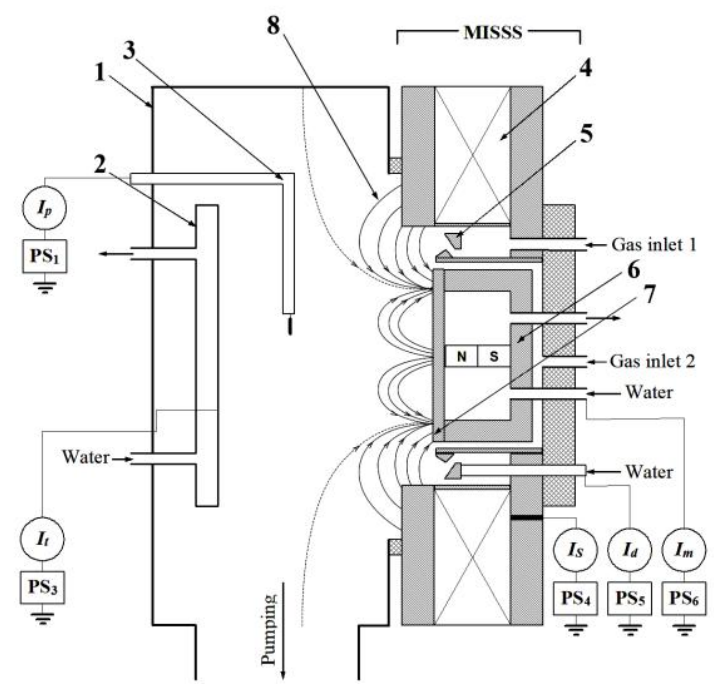

Fig. 1. Schematic diagram of experimental set-up: 1 - vacuum chamber; 2 - water cooled sample holder;

3 - flat probe for ion current density measurement; 4 -solenoid; 5 - anode of ion source; 6-magnetron;

7 - magnetron target; 8 - magnetic force lines

The magnetron body 6 of $76 \mathrm{~mm}$ diameter and $45 \mathrm{~mm}$ in length is made of soft magnetic steel and is mounted on a dielectric flange in the center of the ion source. Permanent magnets with surface magnetic field strength of up to $3.5 \mathrm{kOe}$, are located on the axis of the system inside the magnetron body, which is cooled by water. A 
target 7 of $76 \mathrm{~mm}$ diameter is mounted on the magnetron body with a vacuum seal.

Both the IS and the magnetron possess the common magnetic system. Using the solenoid 4, it is possible to change the configuration of the magnetic field lines (MFL) in the magnetron, and to realize balanced or unbalanced magnetron types. The MFL topologies at various solenoid currents are given in [9].

The experimental setup was built for MISSS characterization and coating deposition experiments (including conductive and dielectric coatings) by magnetron sputtering with variable ion bombardment in wide range of ion energy $(10 \ldots 300 \mathrm{eV})$ and current density $\left(0 \ldots 5 \mathrm{~mA} / \mathrm{cm}^{2}\right)$. The vacuum chamber 1 with dimensions of $240 \times 240 \times 120 \mathrm{~mm}$ was pumped by a turbomolecular pump with throughput of $700 \mathrm{l} / \mathrm{s}$ to the base pressure below $1 \cdot 10^{-5}$ Torr.

To avoid quick transparency loss by viewports due to coating deposition a stainless steel magnetron target and air as a working gas were used to measure the discharge characteristics of MISSS and the parameters of charged particle fluxes.

The flat conductive electrode 2 with diameter of $140 \mathrm{~mm}$ located at $100 \mathrm{~mm}$ distance from the magnetron target is used for sample holding and ion beam monitoring. Radial distributions of ion current density were measured moving $5 \times 5 \mathrm{~mm}$ planar probe radially along the sample holder surface.

During the investigation of integral characteristics of the MISSS, the following parameters were monitored:

$I_{s}$ - solenoid current $(0 \ldots 4 \mathrm{~A})$;

$I_{d}$ - anode current of the ions source $(0 \ldots 400 \mathrm{~mA})$;

$I_{m}$ - magnetron target current $(0 \ldots 1 \mathrm{~A})$;

$I_{t}$ - ion current to the sample holder 2 ;

$I_{p}$ - ion current to the flat probe 3 ;

$U_{d}$-ion source anode voltage $(0 \ldots 2 \mathrm{keV})$;

$U_{m}$ - magnetron target voltage $(0 \ldots 1 \mathrm{keV})$.

The ion source anode voltage is positive while the magnetron voltage is negative, but in the present paper we use the absolute values of the both voltages.

\section{EXPERIMENTAL RESULTS}

The first part of the present paper describes the autonomous operation of the ion source and the magnetron discharge, as well as their main characteristics in dependence on the parameters of the system while using separate power supplies. The next part investigates their mutual influence and the ion flow to the treated surface.

The dependences of the discharge voltage $U$, discharge current $I_{d}$ of the IS and sample table current $I_{t}$ on the pressure in the chamber are presented in Fig. 2.

The figure shows that when the gas pressure in the discharge gap reaches the critical value $p=0.6 \ldots 1$ mTorr the discharge transits from acceleration (high-voltage) mode to plasma (high-current) mode. In contrast to similar characteristics of the ion source with a discharge gap of $5 \mathrm{~mm}$ presented in $[9,10]$ the transition from acceleration mode to plasma mode has shifted to a lower pressure region (previously it was $3 . .4$ mTorr), as well as the influence of the working gas feeding through different channels has also disappeared.

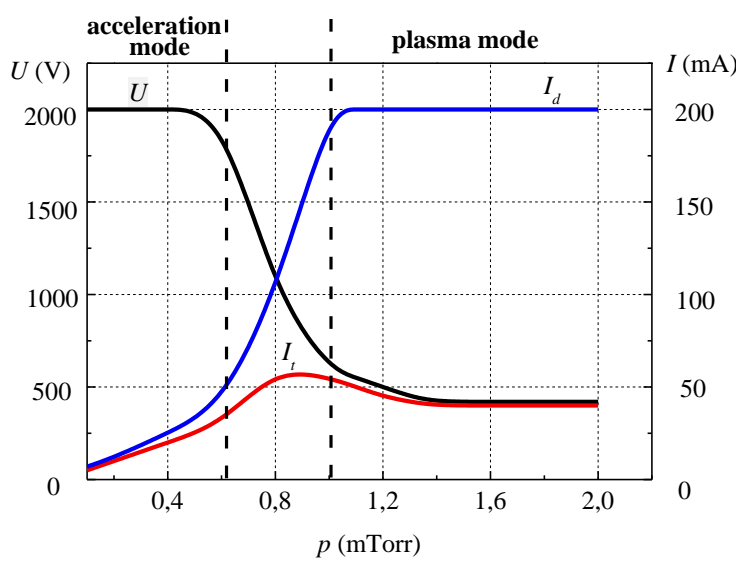

Fig. 2. The dependences of the discharge voltage $U$, discharge current $I_{d}$ of the IS and target current $I_{t}$ on the pressure in the working chamber. $I_{s}=2 \mathrm{~A}$

The ignition curves of discharge in the ion source are typical and presented in [9]. Ignition curves of the magnetron discharge for different solenoid currents are presented in Fig. 3.

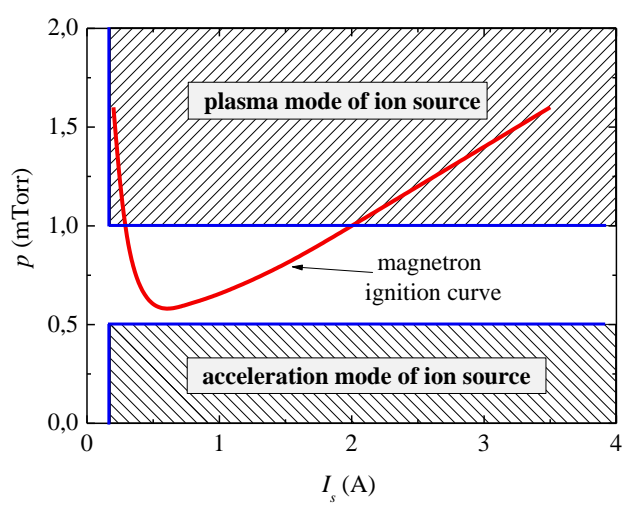

Fig. 3. Ignition curves of discharge in the ion source at different Argon pressures

At $I_{s}<0.75 \mathrm{~A}$ the unbalanced magnetron of the first type is realized, when a significant part of the MFL starting from the target terminate at the walls of the vacuum chamber.

At $0.75 \mathrm{~A}<I_{s}<1.25 \mathrm{~A}$, when almost all MFL starting from the center of the target terminates at the target the balanced magnetron mode takes place.

At $I_{s}>1.25$ A the unbalanced magnetron discharge of the second type appears, when the peripheral MFL are terminated at the sample holder that focuses the electron flow.

As it can be seen from the figure, the deviation of the MFL topology from the balanced magnetron $\left(I_{s}=0.75 \mathrm{~A}\right)$ leads to significant increase in the minimum pressure of magnetron discharge existence. The region of magnetron discharge existence and the plasma regime of the ion source overlap in terms of the working gas pressure and the magnetic field strength at $p>1$ mTorr and $H>300$ Oe.

Fig. 4 shows the current-voltage characteristics (CVC) of the ion source in plasma mode at $p=2 \cdot 10^{-3}$ Torr. 


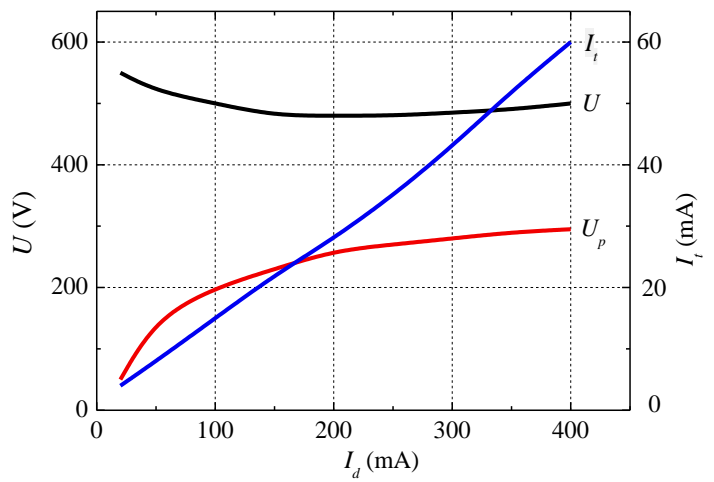

Fig. 4. CVC of ion source in plasma mode. Air pressure $p=2 \cdot 10^{-3}$ Torr

The figure also presents the dependence of the ion current to the sample table $I_{t}$ and the floating potential of the probe $U_{p}$. As follows from the given graphs, the ion current to the table is linear and amounts to $(0.2 \ldots 0.25) I_{d}$, depending on the pressure, while the floating potential grows monotonically with $I_{d}$ increase and reaches a value of about $1 / 2$ of anode voltage $U$.

Dependencies of the discharge voltage $U$, sample table current $I_{t}$ (the table is biased to $-100 \mathrm{~V}$ ), and the probe floating potential $U_{p}$ on the magnetron discharge current $I_{d}$ are presented in Fig. 5.

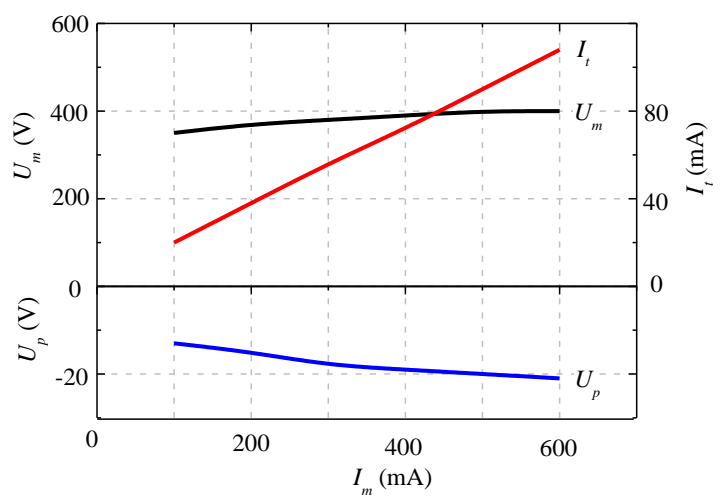

Fig. 5. CVC, substrate table current $I_{t}$ (biased to -100 $V)$, and floating potential vs. the magnetron current $I_{d}$. Argon pressure $p=2 \cdot 10^{-3}$ Torr

One can see from the figure that the shape of currentvoltage characteristic of the magnetron discharge is similar to CVC of the IS in the plasma mode (see Fig. 4). The ion current to the substrate holder also increases linearly with the magnetron discharge current increase. However, the floating potential of the probe in the plasma near the sample holder is negative with voltage near $15 \ldots 20 \mathrm{~V}$.

The MFL configuration is determined by the ratio between the solenoid magnetic field strength and the field of central permanent magnet. As our experiments have shown, with the change of MFL topology the main characteristics of the magnetron discharge are substantially changed, particularly the existence region of the discharge over the gas pressure (see Fig. 3) and CVC. The dependences of IS parameters $U, U_{p}, I_{t}$ on the solenoid current $I_{s}$ are presented in Fig. 6.

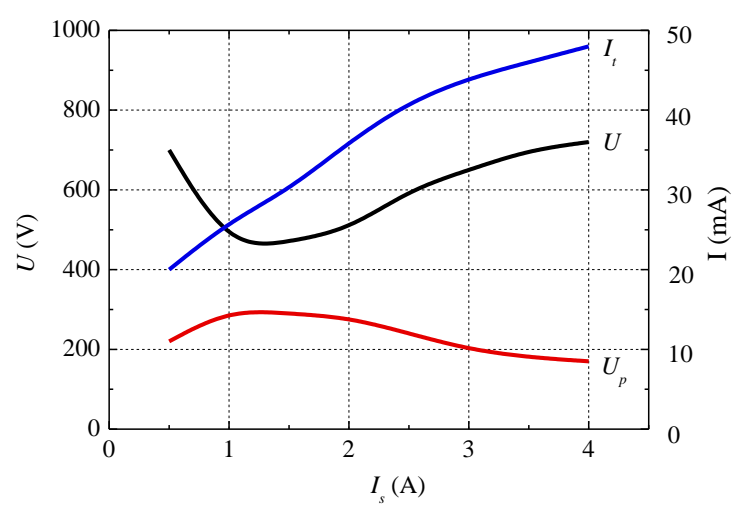

Fig. 6. Dependences of IS parameters $U, U_{p}, I_{t}$ on the solenoid current $I_{s}$. Air pressure $p=1.5 \mathrm{mTorr}$

As it follows from the graphs shown in Fig. 6, the minimum discharge voltage is about $450 \mathrm{~V}$, and the plasma potential drop in the anode region $\left(U-U_{p}\right)=$ $200 \mathrm{~V}$ are observed in the range $I_{s} \approx 1 \ldots 1.5 \mathrm{~A}$. This range corresponds to the minimum energy of ions bombarding the growing film surface.

Fig. 7 shows the radial ion current density distributions to a flat probe $j_{i}(R)$ at various distances from the ion source operating in plasma mode.

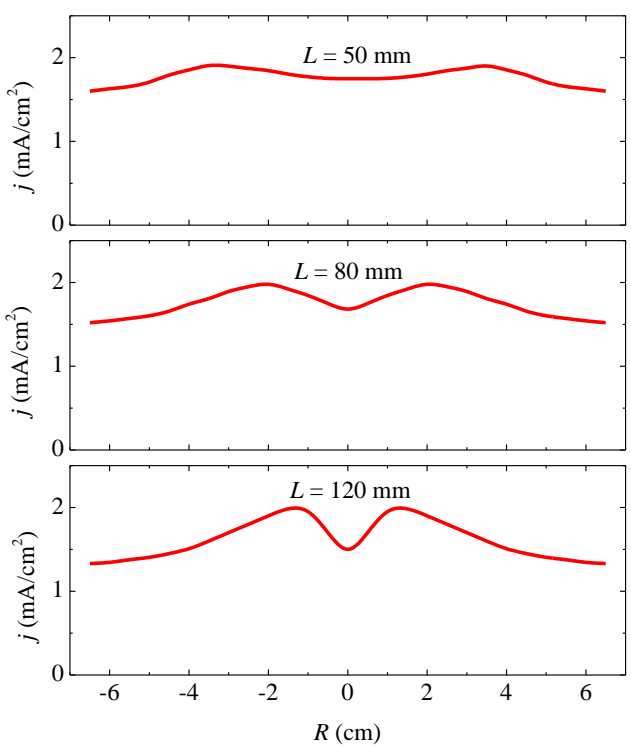

Fig. 7. Radial distributions of ion current density $j_{i}(R)$ in the plasma mode of IS at different distances from IS

These data indicate that two regions of gas ionization are present in the plasma mode: 1) the anode region where the ion beam converging to the substrate holder is formed; 2) secondary plasma occupying the entire volume of the working chamber.

The ions generated in the secondary plasma do not have directional movement and bombard the entire surface bounding the plasma, including the substrate holder and sidewalls of the chamber.

For comparison, Fig. 8 shows radial distribution of $j_{i}(R)$ at the distance of $120 \mathrm{~mm}$ from the ion source in acceleration mode ( $p=0.6$ mTorr) and plasma mode ( $p=1.5$ mTorr) for IS version with the cathode gap of $5 \mathrm{~mm}$, presented in [9]. 


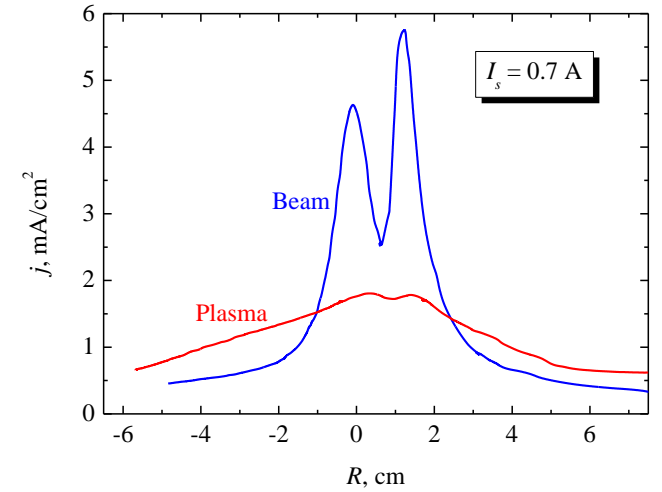

Fig. 8. Radial distribution of ion current density in the acceleration and plasma modes of ion source, presented in [9]

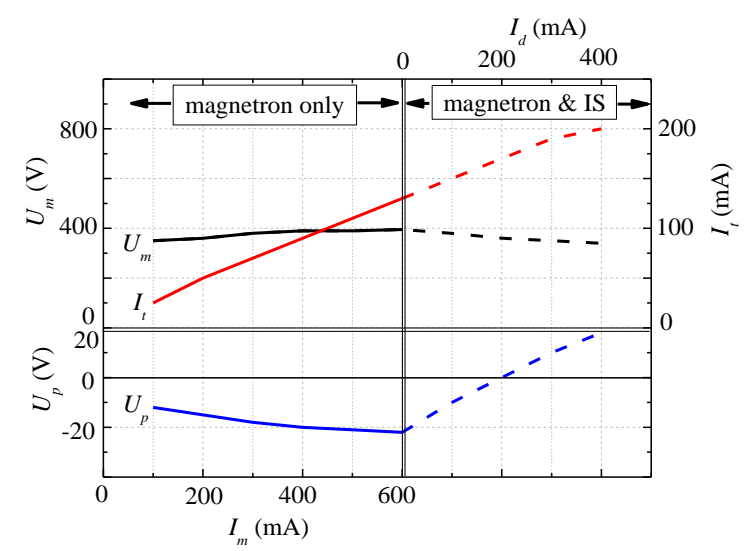

Fig. 9. Combined CVC of the system, ion current $I_{t}$ to the substrate holder, and floating potential $U_{p}$ vs. $I_{m}$ and $I_{d}$

Separate operation of the magnetron and the ion source is described above. However, this information is not sufficient for understanding the peculiarities of simultaneous operation of them. The both discharges have common element, namely, the secondary plasma appearing in the volume between MISSS and substrate holder. Experiments show that the discharges experience significant mutual influence. Nevertheless, we can derive some regularities characterizing the joint operation of the both devices.

Combined CVC of the system is presented in Fig. 9. It was measured in the following sequence. First CVC of the magnetron discharge was measured in the range $I_{m}=0 \ldots 600 \mathrm{~mA}$, while the ion source operated at minimum discharge current $I_{d}=10 \mathrm{~mA}$. Then, at constant magnetron current $I_{m}=600 \mathrm{~mA}$ the IS current $I_{d}$ was increased to $400 \mathrm{~mA}$. The ion current $I_{t}$ to the substrate table (biased at $-100 \mathrm{~V}$ ) and floating potential of the probe $U_{p}$, are shown in the same graph.

The most interesting in the presented results is the fact that the ion current from the source is able to compensate (and even overcompensate) the electron flux from the magnetron discharge, that is proven by the change in the floating potential from -20 to $+20 \mathrm{~V}$. This feature is of great importance for dielectric films deposition allowing control of the dielectric surface potential and energy of bombarding ions.
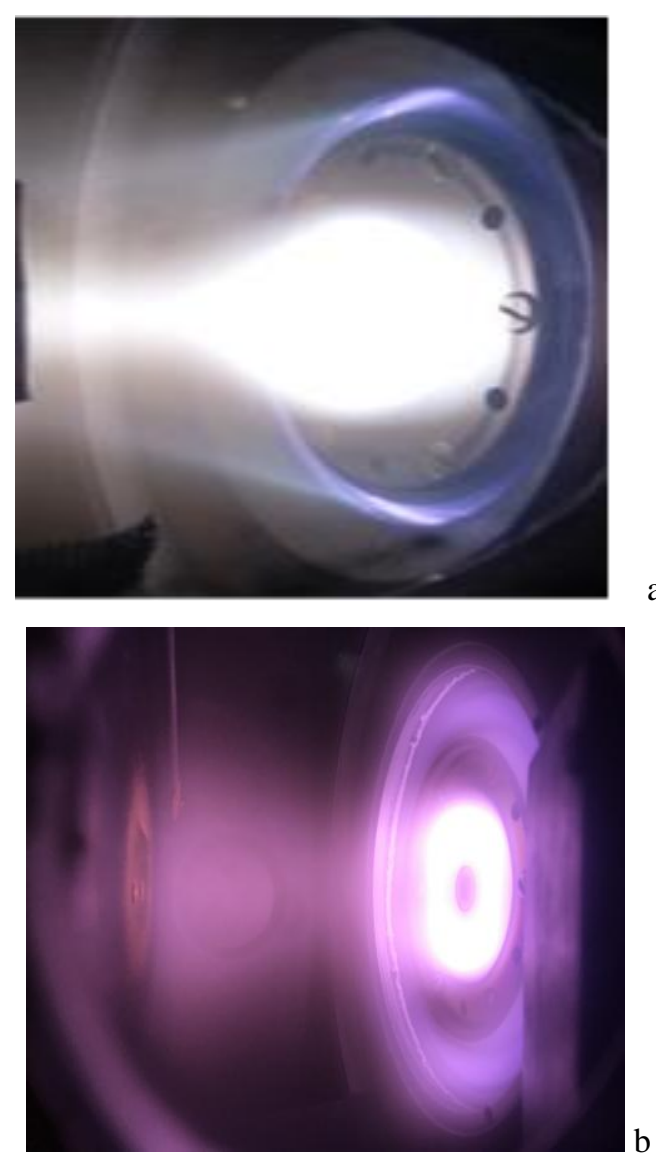

Fig. 10. Images of MISSS during the simultaneous operation of the magnetron discharge and the ion source in acceleration ( $a$ ) and plasma (b) modes

The flux of low-energy ions onto the substrate holder generated in the magnetron discharge plasma linearly depend on the magnetron current, while the flux of high-energy ions from the near-anode region of IS is proportional to the anode current. It is important that during the joint operation the currents are summed (see Fig. 9), and may be controlled independently in a wide range $(0 \ldots 0.3 \mathrm{~A})$.

Fig. 10 shows images of the MISSS during the simultaneous operation of the magnetron discharge and the ion source in acceleration (a) and plasma (b) modes.

\section{CONCLUSIONS}

The main result of this work is the demonstration of the fundamental possibility of combining a planar magnetron discharge and a low-energy Hall-type ion source into the joint discharge device. In terms of electrode configuration and MFL topology, the system may be considered as a magnetically isolated triode. Conducted research of discharge characteristics of the combined system have shown that the main regions of active ionization of the working gas are the following.

- Cathode region of the magnetron discharge. The ion flow sputtering the magnetron target as well as the electron flow to the substrate holder are generated in this region. 
- Anode region of the ion source. It is located near the magnetically insulated anode of IS. A significant part of the electrons in this region drifts from the secondary plasma across the magnetic field towards the anode ionizing the gas intensively. The created ions form a conical ion beam converging to the substrate holder. They possess higher energy than plasma ions.

- Secondary plasma. It is located in the space between the substrate holder and the magnetron target. In this region a flow of low-energy ions is generated.

Investigation of the discharge characteristics during simultaneous operation of magnetron and ion source has shown a number of positive features of this approach:

1. The activation by the ion source (even with a small discharge current of about $10 \mathrm{~mA}$ ) leads to a significant $(1.5 \ldots 2$ fold $)$ decrease in the minimum pressure of the magnetron discharge existence.

2. The presence of the ion beam leads to decrease in the magnetron discharge voltage by $50 \ldots 100 \mathrm{~V}$ and stabilizes its operation at a gas pressure less than $10^{-3}$ Torr.

3 . The unique feature of the system is that it generates the bipolar flow of ions and electrons towards the treated surface with the ability to regulate their ratio over a wide range. In particular, the generation of a quasi-neutral flux is possible, enabling dielectric film deposition with high-energy ion bombardment using direct current.

At the same time, the design of the MISSS allows using a common power supply for the ion source and magnetron discharge. In this case, the MISSS represents a magnetically isolated triode discharge with a floating electrode, which is the subject of further research.

\section{REFERENCES}

1. J.A. Thornton. Substrate heating in cylindrical magnetron sputtering sources // Thin Solid Films. 1978, v. 54, № 1 , p. 23-31.

2. J. Musil. Low-pressure magnetron sputtering // Vacuum. 1998, v. 50, № 3,4, p. 363-372.

3. R.D. Arnell, P.J. Kelly. Recent advances in magnetron sputtering // Surf. Coat. Technol. 1999, v. 112, p. 170-176.

4. Musil. Flexible Hard Nanocomposite Coatings // RSC Advances. 2015.

5. I. Petrov, F. Adibi, and J.E. Greene. Average energy deposited per atom: A universal parameter for describing ion assisted film growth? // Surf. Coat. Technol. 2019, v. 377, p. 124887.

6. A.V. Zykov, S.D. Yakovin, S.V. Dudin. Synthesis of dielectric compounds by DC magnetron // Physical Surface Engineering. 2009, v. 7, № 3, p. 195-203.

7. S. Yakovin, S. Dudin, A. Zykov, V. Farenik. Integral cluster set-up for complex compound composites syntesis // Problems of Atomic Science and Technology. Series “Plasma Physics”. 2011, № 1, p. 152-154.

8. V. Zhurin. Industrial Ion Sources. Wiley-VCH Verlag and Co. KGaA, 2012.

9. S. Dudin et al. Design and research of combined magnetron-ion-beam sputtering system // Problems of Atomic Science and Technology. Series «Plasma Physics». 2018, № 6(118), p. 263-266.

10. A. Zykov et al. Combined Magnetron-Ion-Source System for Reactive Synthesis of Complex Nanostructured Coatings // Microstructure and Properties of Micro- and Nanoscale Material / Eds. A. Pogrebnjak, O. Bondar. Films, and Coatings (NAP 2019). Springer Proceedings in Physics, v. 240, Springer, Singapore, 2020, p. 161-175.

Article received 11.10.2020

\title{
РАЗРЯДНЫЕ ХАРАКТЕРИСТИКИ КОМБИНИРОВАННОЙ НИЗКОЭНЕРГЕТИЧНОЙ ИОННО-ЛУЧЕВОЙ МАГНЕТРОННОЙ РАСПЫЛИТЕЛЬНОЙ СИСТЕМЫ
}

\author{
А. Зыков, Н. Ефименко, С. Дудин, С. Яковин
}

Проведены исследования разрядных характеристик новой комбинированной низкоэнергетичной ионнолучевой магнетронной распылительной системы с удельными параметрами, отвечающими требованиям промышленного производства. Исследованы кривые зажигания, разрядные характеристики в зависимости от давления рабочего газа, величины и топологии магнитного поля как при автономной, так и при совместной работе планарного магнетронного разряда и источника ионов холловского типа в плазменном режиме. Исследованы пространственные характеристики потоков ионов.

\section{РОЗРЯДНІ ХАРАКТЕРИСТИКИ КОМБІНОВАНОЇ НИЗЬКОЕНЕРГЕТИЧНОЇ ІОННО-ПРОМЕНЕВОЇ МАГНЕТРОННОЇ РОЗПОРОШУВАЛЬНОЇ СИСТЕМИ}

\section{О. Зиков, Н. Сфименко, С. Дудін, С. Яковін}

Проведено дослідження розрядних характеристик нової комбінованої низькоенергетичної іоннопроменевої магнетронної розпорошувальної системи з питомими параметрами, які відповідають промисловому виробництву. Досліджено криві запалювання, розрядні характеристики в залежності від тиску робочого газу, величини та топології магнітного поля як при автономній, так і при сумісній роботі планарного магнетронного розряду та джерела іонів холлівського типу у плазмовому режимі. Досліджені просторові розподіли потоків іонів. 